movement. A cover over all keeps the light out from the rear of the instrument. It will be noted that during the instant of exposure, the sensitised surface is steady, and when the exposure is over, it is at once passed away. Pressure on the button (b, Fig. 2,1$)$ sets the machine in motion. Before applying this instrument to the study of the flight of birds, an experiment was made with it on a black arrow, made to rotate against a white back-ground well lit up. The speed of the rotation of the arrow was about 5 metres a second. The marksman, at a distance of ro metres sighted on the centre of the target, on which the eye could perceive nothing save a confused grey shadow, so quick was the rotation of the arrow : but on the development being completed, twelve images were to be seen, disposed in a circular manner, and each showed not only the arrow, but its shadow, as sharp as if the original had been immovable. Another experiment, equally successful, was made on a pendulum beating seconds. For to be more certain as to the duration of the exposure, M. Marey next adapted to the gun a chronographic apparatus, so that the time intervening between the taking of each picture could be with precision ascertained. After all these preliminary essays, the photography of animals in movement was attempted; and in Fig. 3 there will be seen the photographic representations of a sea-gull, in which the twelve successive attitudes assumed during the space of a single second by this bird during flight are ascertained. On other occasions other success-

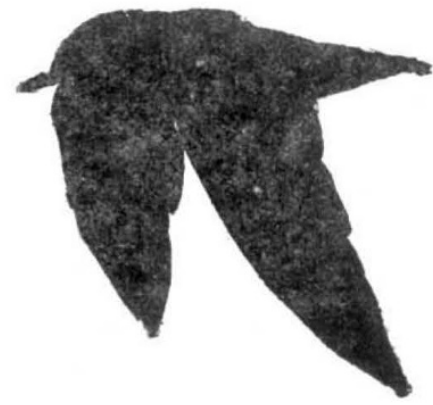

FIG. 5.-Sea.gull; end of depression of wing.

ful photographic series of a sea-gull in flight were taken when the bird was seen less in profile. The sea-gull gave exactly three strokes of its wing each second, so in the twelve photographs of each stroke four succeeding stages were reproduced. The wings at first elevated to their greatest, then commence to be lowered ; then in the following image they are seen at the lowest point of their course and in the fourth image are again on the rise. In enlarging these images, figures seen from a good distance were obtainable, but the sharpness of the enlargements left a good deal to be desired ; for the negatives were somewhat granular, no doubt owing to some slight fault in the photographic process. The reproduction of these images by the heliographic process gives excellent silhouettes (as seen in Figs. 4 and 5 ); the originals, when examined under the microscope, showed even the wing-feathers distinctly.

On comparing the indiations thus given by the photographic process with those already attained by the graphic process, a confirmation of most of the principal points obtained by the latter were obtained; but otherwise so far, the latter did not seem to add much to our knowledge of the mechanism of flying. However, ere deciding that this is so, numerous observations on different birds flying and in different conditions of flight, during calms and storms, and with and against the wind, must be taken. Attempts were also made to photograph the bat, but its small size, its flight during the dusk, and its capricious method of flying made it a difficult subject; but some of the experiments revealed interesting results. The angle of oscillation of its wings is very extended, especially from below, when the two wings form two vertical planes sensibly parallel.

These extremely interesting researches of M. Marey are only, as it were, in their infancy; he intends pursuing them much further, and his results will be looked for with great interest by all those who study the subject of animal motion.

\section{DR. FRITZ MÜLLER ON SOME DIFFICULT CASES OF MIMICRY}

I $\mathrm{N}$ his original explanation of the cause of mimicry, Mr. Bates referred to the occurrence of many cases in which species of different genera of Heliconidæ resemble each other quite as closely as the mimicking Leptalides and Papilios resemble species of Ithomia and other Heliconoid butterflies. In these cases both the imitating and the imitated species are protected by distastefulness, and it was not therefore clear how the one could derive any benefit by resembling the other. Accordingly, Mr. Bates did not consider these to be true cases of mimicry, but to be due, either to identical parallel variations of externally similar form, or "to the similar adaptation of all to the same local, probably inorganic, conditions."

Examples of this close resemblance of species of different genera of protected groups have now become very numerous, and they often extend to three or more distinct genera, some species of which imitate each other in most parts of tropical America, each changing in a corresponding: manner as we pass from one district to another.

In my Address to the Biological Section of the British Association at Glasgow, in 1876 (reprinted in "Tropical Nature"), I connected these cases with a number of others in which peculiarities of colour or of form appear together in several groups not closely allied, but always among those inhabiting the same locality and as frequently among unprotected (that is, eatable) as among protected groups of butterflies; and I concluded, generally, as Mr. Bates had done, that these curious phenomena were due to "unknown local causes."

Thus the matter rested, till, in 1879 , Dr. Fritz Müller published in Kosmos a paper on "Ituna and Thyridia ; a remarkable case of Mimicry in Butterflies"; and in $188 \mathrm{r}$ a second paper, entitled "Remarkable cases of acquired resemblance among Butterflies," in which he gives a solution of the problem as really a case of mimicry. The first of these papers was translated by Mr. R. Meldola, and communicated to the Entomological Society of London in May, 1879 , and the same gentleman has kindly furnished me with a translation of the second paper (the title of which is given below), which discusses the whole question in great detail, and devotes much spa:e to a criticism of my suggested "unknown local causes" as a sufficient explanation of the phenomena. I may at once say that I admit this criticism to be sound; and that Dr. F. Müller's theory appears to me to afford a clue (with some slight modifications) to most of the cases of close individual resemblance of not-nearly-related species of butterflies yet observed. I therefore wish to state, as briefly as possible, the exact nature of the explanation now afforded us, and this is the more necessary because Dr. Müller's theory did not receive much support when brought before the Entomological Society, nor did it then satisfy Mr. Bates, the discoverer of the true meaning and importance of the phenomena of mimicry as interpreted by the doctrine of Natural Selection.

The explanation depends on the assumption, that some at least, if not all, young insectivorous birds learn by experience that the Heliconoid butterflies are distasteful, and in so doing sacrifice a certain number of individuals

I "Bemerkenswerthe Fälle erworbener Aehnlichkeit bei Schmetterlingen." Von Fritz Mül!er. (Separat-Abdruck aus "Kosmos," V. Jahrgang, I88r.) 
of each distinct species. But if two species, both equally distasteful, closely resemble each other, then the number of individuals sacrificed is divided between them in the proportion of the square of their respective numbers; so that if one species $(a)$ is twice as numerous as the other $(b)$, then $b$ will only lose one-fourth as many individuais as it would do if it were quite unlike $a$; and if it is only one-tenth as numerous then it will benefit in the proportion of Ioo to I. It is an undoubted fact that the species of protected butterflies, like those of other groups, differ greatly in abundance of individuals, some being very rare while others are among the commonest of all butterflies. The proportion of ICO to I, therefore, is far below the amount of benefit an uncommon species might derive by resembling a common one. The benefit to be derived is thus clear, if the protected species are subject to the danger of attacks by young birds before they learn that such species are uneatable. I agree with Dr. Müller that they are exposed to this danger; and when we consider the great number and variety of insectivorous birds in South America the danger must be considerable, and quite sufficient to render it important for a numerically weak species to reduce it to a minimum, although to a sfecies abounding in individuals it may be of little importance. It has been suggested that young birds have an hereditary instinct enabling them to distinguish uneatable butterflies antecedent to experience; but this seems in the highest degree improbable. It has no doubt been shown by Mr. Darwin that monkeys in captivity have a dread of snakes, and Mr. Jenner Weir believes that birds have an instinctive knowledge of uneatable caterpillars. But even admitting that in these two cases there is an instinctive hereditary aversion, it does not follow that the same will occur with regard to protected butterfiles. Snakes form one well-marked group, and it is not alleged that monkeys distinguish between poisonous and harmless snakes ; and caterpillars can also be readily divided into the two classes of edible and inedible by their green or brown (protective) colours on the one hand, and their gaudy or conspicuous colouration or hairy bodies on the other. But the protected butterflies have no such general mark of inedibility. Their colours and forms vary greatly, and cannot as a group be readily differentiated from those of other butterflies; and it is not to be accepted without actual proof that a young bird knows instinctively every Heliconoid or Danacoid butterfly in its district, as well as the protected Papilios and moths, almost infinitely varied as they are in colour and marking, among the equally numerous and equally varied butterflies of other groups. It therefore seems clear to me that we have here a vera causa for the acquisition of true protective mimicry by the less abundant species of inedible butterflies.

There is however yet another cause which may have led to mimicry in these cases, and one which does not appear to have been discussed by Dr. Müller. The fact that the majority of butterflies are edible and are actually eaten by birds and other insectivorous creatures, while a considerable minority are distasteful and are thus protected, renders it pretty certain, a priori, that there exist many degrees of distastefulness. Certain species appear to be rejected by all insectivorous creatures, while some, though not eaten by birds, may be devoured by lizards, dragon-flies, or spiders. Some, too, may be eaten by some birds and rejected by others, and no ornithologist will think it strange or improbable that a trogon should have somewhat different tastes from a tyrant-shrike or a swallow. Again, in some species the distastefulness may extend to all the stages of egg, larva, pupa, and perfect insect, while in others it may be confined to one or more of these stages; or special dangers may exist for one species which are absent in the case of another. But it is evident, that, if these differences exist, it will be advantageous for the less protected to mimic the more com- pletely protected species, and the fact of the affinity between the different genera, with perhaps some tendency to revert to a common style of colouration or marking, will afford facilities for the development of this class of mimicry even greater than occur in the case of the distinct and often remote families of completely unprotected butterflies. We need not, therefore, be surprised to find whole series of species of distinct genera of Heliconoid butterflies apparently mimicking each other; for such mimicry is antecedently probable on account of the greater need of protection of some of these species than others, arising either from some species being less distasteful to certain enemies, or less numerous, and therefore likely to suffer to a serious extent by the attacks of inexperienced birds. When these two conditions are combined, as they often would be, we bave everything necessary for the production of mimicry.

The explanation now given, so far as it refers to the various degrees of protection, may be extended to explain those cases in which various groups of Nymphalidæ or other families appear to mimic each other; such as Catagramma, Callithea, and Agrias in one series, and Apatura with Heterochroa in another. In my "Tropical Nature" (p. 257) I have remarked-" "Here, again, neither genus is protected, and the similarity must be due to unknown local causes"; but this is more than we know, and I now think that some of these groups-perhaps Catagramma and Heterochroa-are partially protected, and the advantage of sharing in this partial protection has led species of altogether unprotected and much persecuted groups to gain some protection by mimicking them, whenever their general form, habits, and style of coloration offered a suitable groundwork for variation to act upon.

If these views are correct we shall have the satisfaction of knowing that all casés of mimicry are explicable by one general principle; and it seems strange to me now that I should not have seen how readily the principle is applicable to these abnormal cases. The merit of the discovery is however wholly due to Dr. Fritz Müller; and it is to be hoped that he will complete his work by obtaining, if possible, evidence of its correctness. The chief thing required is an experimental proof of various degrees of inedibility in butterflies, during the different stages of their life-history; and also some observations as to the comparative abundance of the species of protected butterflies which mimic each other. If to this can be added the proof that such groups as Catagramma, which seem to be the objects of mimicry, are partially protected by inedibility, the chief remaining difficulty in the application of the theory of natural selection to all known cases of protective imitation will have been cleared up.

\section{ALFRED R. WALLACE}

\section{NOTES}

IN reference to the Darwin Mem rrial, to which we referred last week, the honorary secretaries have issued a circular asking for contributions to the fund. In this memorial it is stated that though the works of Charles Darwin are his best and most enduring memorial, it is felt by his many friends and admirers that these should not be the only one. They are desirous of handing down to posterity the likeness of a man who. has done so much for the advancement of natural knowledge. They wish also to establish a fund associated with his name, the proceeds of which will be devoted to the furtherance of biological s cience A committee has accordingly been formed, of which Mr. T. G. Bonney and Mr. P. Edward Dove are the hon. secretaries. The committee is one of the highest influence, comprising the leading foreign ministers, the two Archbishops, and the best-known names in all ran's and professions.

JOHANN CARL Friedrich ZOLlLNer, whose death we recently announced, was born at Berin on November 8, 1834 . 